Original research article

\title{
Beneficial effects of Stevioside on AGEs, blood glucose, lipid profile and renal status in streptozotocin-induced diabetic rats
}

\author{
Urmila Aswar ${ }^{1 *}$, Vinayak Gogawale ${ }^{2}$, Pankaj Miniyar ${ }^{2}$, Yugendra Patil ${ }^{3}$ \\ ${ }^{1}$ Bharati Vidyapeeth (Deemed to be University), Poona College of Pharmacy, Erandwane, Pune, Maharashtra, India \\ 2 STES's Sinhgad Institute of Pharmacy, Savitribai Phule Pune University, Narhe, Pune, Maharashtra, India \\ ${ }^{3}$ National Chemical Laboratory, Pune, Maharashtra, India
}

\section{Abstract}

The advanced glycated end products (AGEs) are formed in the diabetic patients; it is a major cause of macrovascular and microvascular complications in diabetes. Clinically there is no treatment available for the AGEs. Stveoside (Stv), a sweetener has potent anti-diabetic and anti-oxidant activity. Hence, we investigated its use in prevention of AGEs formation using in vitro and in vivo models. Diabetes was induced by streptozotocin (STZ). These rats were kept without treatment till blood HbA1c was markedly increased. They were then divided into 5 groups and treated orally with vehicle or Metformin (MET) or Stv respectively for 28 days. Every 7th day, animals were tested for body weight and blood glucose (BG). On the last day of treatment, all the groups were evaluated for physiological and biochemical parameters, histopathology and AGEs; $N$-carboxymethyl-lysine (CML) estimation. Stv showed inhibition of AGEs in in vitro as well as in in vivo respectively. Positive effects were seen on the BG, lipid profile and urine parameters as well it showed reduced formation of CML. It also showed antihyperglycaemic, antihyperlipedemic and nephroprotective activities. The present study provides scientific rationale for the use of Stv as a sweetener with additional benefits in diabetes.
\end{abstract}

Keywords: AGEs; Diabetes; Diabetes complications; $N$-carboxymethyl-lysine; Stevioside; Streptozotocin

\section{Highlights:}

- Persistent and untreated hyperglycemia through HbA1c may lead to diabetic vascular complications.

- Clinically, there is no treatment available for glycation prevention.

- Stevioside glycoside is a natural sweetener, exhibits insulinotropic, glucagonostic, anti-hyperglycemic effect.

- We found it to reduce glycation as well as it showed potent antihyperglycaemic, antihyperlipedemic and nephroprotective activities.

\section{Introduction}

Diabetes mellitus is a global issue affecting children, adults and adolescents (Pinhas-Hamiel et al., 2015). Persistent and untreated hyperglycemia may lead to diabetic vascular complications through many metabolic and structural changes, such as the production of advanced glycation end products (AGEs). Accumulation of AGEs alters many extracellular and intracellular structures and functions (Brownlee, 1995) that may result in diabetic complications such as retinopathy, cardiomyopathy, nephropathy and neuropathy (Goh and Cooper, 2008; Jakus and Rietbrock, 2004).

Free amino groups of proteins, lipids and nucleic acids with the carbonyl group $(-\mathrm{C}=\mathrm{O})$ of reducing sugars react and result in production of glycated products (Daroux et al., 2010). Some examples are hemoglobin, human serum albumin, collagen and high, low-density lipoproteins that are more prone to the formation of AGEs (Ansari and Ali, 2011). The reaction between glucose and amino acids is reversible and it forms the Schiff's base by hydrolysis, the Schiff's base rearranges to an early glycation product known as Amadori product which is the more stable form of reaction (Bohlender et al., 2005). Examples of AGEs are $N$-carboxymethyl-lysine (CML), pentosidine, or methylglyoxal (Peppa et al., 2008). Vitamin B6, LR 90, $N$-phenacylthiazolium, vitamin C, vitamin E, benfotiamine, have shown antiglycating activity in vivo and in vitro (Chang et al., 2014; Elosta et al., 2012; Figarola et al., 2003; Naowaboot et al., 2009), aminoguanidine appeared to be first potent AGE inhibitor in preclinical studies. However, due to ambiguity in their clinical efficacy their use is limited.

Therefore, the diet and drugs from natural sources is the mainstay for the management of diabetes and its complications. The deficiency of available treatment of diabetes-induced glycation, prompted us to test naturally occurring stevioside glycoside (Stv). It's a natural sweetener, 250 times

\footnotetext{
* Author for correspondence: Urmila M. Aswar, Bharati Vidyapeeth (Deemed to be University), Poona College of Pharmacy, Erandwane, Pune - 411038, Maharashtra, India; e-mail: aswarurmila@gmail.com http://doi.org/10.32725/jab.2019.013

Submitted: 2018-10-16 • Accepted: 2019-06-24 • Prepublished online: 2019-08-21

J Appl Biomed 17/3: 190-197• EISSN 1214-0287 • ISSN 1214-021X

(c) 2019 The Authors. Published by University of South Bohemia in České Budějovice, Faculty of Health and Social Sciences.

This is an open access article under the CC BY-NC-ND license.
} 
sweeter than sucrose and is utilized widely as a sugar substitute in diet (Gardana et al., 2003). It is obtained from plant Stevia rebaudiana Bertoni, belonging to family Asteraceae. It is reported to exhibit insulinotropic, glucagonostic, anti-hyperglycemic (Gregersen et al., 2004; Jeppesen et al., 2000, 2002), anti-hypertensive (Hsieh et al., 2003; Jeppesen et al., 2003; Liu et al., 2003), immunomodulator (Boonkaewwan et al., 2008; Sehar et al., 2008) and antioxidant property (Stoyanova et al., 2011). Stv as such is not absorbed orally, it is metabolized by the intestinal microflora and forms an aglycon metabolite steviol (Gardana et al., 2003).

\section{Materials and methods}

\section{Chemicals}

Stv was procured from Desle Agro Ltd. (India). STZ was purchased from Enzo Life Sciences (USA), Metformin (Met) was provided as a gift sample from Dr. Reddy's lab (India), CML antibody raised in Rabbit (ab27684) was procured from Abcam (UK), anti-rabbit HRP secondary antibody was used in blot purchased from Merck Millipore (India), and protein estimation kit (Bio-Rad chemicals, USA) was purchased. Secondary antibody-biotin conjugate, secondary antibody-HRP were purchased from Merck Millipore, (India). Other chemicals, bovine serum albumin, sodium azide, glucose, urea, thiourea, 3-[(3-cholamidopropyl)dimethylammonio]-1-propanesulfonate, dithiothreitol, tris base, acrylamide, glycine, ammonium persulfate, tetramethylethylenediamine, bis acrylamide, sodium dodecyl sulphate were purchased from Sigma-Aldrich (USA). All other biochemical kits were purchased from Coral Clinical Systems (India).

\section{Animals}

Adult male Wistar rats $(250-300 \mathrm{~g})(n=30)$ were procured from the institutional animal house (Reg. No.: 1139/a/07/ CPCSEA) and were housed in diurnal lighting condition $(12 \mathrm{~h} / 12 \mathrm{~h})$ with a temperature of $25 \pm 1{ }^{\circ} \mathrm{C}$, relative humidity of $45-55 \%$. Animals had free access to food (Standard Chow Pellet, Nutrivet Life Sciences, Pune) and water ad libitum. The experimental protocol was approved by the Institutional Animal Ethical Committee (IAEC) of Sinhgad Institute of Pharmacy, Narhe, Pune constituted as per the Committee for Purpose of Supervision and Control on the experimental animal (CPCSEA), (IAEC protocol approval No. SIOP/IAEC/2015/13).

\section{In vitro glycation study}

Stevioside was made available in powder form. Weighed quantity Stv powder was dissolved in water. The different concentrations of Stv ranging from $50 \mathrm{mM}$ to $300 \mathrm{mM}$ were selected. These concentrations were incubated with $25 \mathrm{mg} / \mathrm{ml} \mathrm{BSA}$ and $0.5 \mathrm{M}$ glucose and sodium azide $(0.05 \%)$ in $0.1 \mathrm{M}$ phosphate buffer at $\mathrm{pH}$ 7.4. The reaction volume was adjusted to $600 \mu \mathrm{l}$ using sterile water. This reaction mixture was incubated for 30 days at temperature $37{ }^{\circ} \mathrm{C}$ (Sajithlal et al., 1998). Similar procedure was followed for BSA and glucose and BSA alone without Stv. Fluorescence reading was recorded by using Varioskan flash multiplate reader ${ }^{\circledR} .200 \mu \mathrm{l}$ reaction mixture was taken in 96-wells flat bottom plate. Fluorescent AGEs were measured at excitation of $370 \mathrm{~nm}$ and emission wavelength at $440 \mathrm{~nm}$. Complete inhibition of glycation was said to occur when fluorescence was reached to that of albumin in absence of glucose. The percent inhibition of glycation by Stv was calculated using the formula:

$$
\% \text { inhibition }=\left(\text { glycated BSA }-\frac{\text { Test }}{\text { glycated }} \text { BSA }\right) \times 100
$$

The graph was plotted with percent inhibition vs concentration.

\section{Induction of diabetes}

Overnight fasted animals were rendered diabetic by a single i.p. injection of STZ (35 $\mathrm{mg} / \mathrm{kg}$ body weight) in freshly prepared cold citrate buffer (0.1 M, pH 4.5), whereas Group 1, vehicle control rats were injected with the same amount of vehicle (distilled water). STZ administered animals were given 5\% glucose solution for $24 \mathrm{~h}$. On the third day, the blood glucose levels under ad libitum feeding were measured, and rats with blood glucose levels higher than $250 \mathrm{mg} / \mathrm{dl}$ were deemed as diabetic rats. These rats were divided into 4 groups as Group 2 STZ treated, Group 3 was treated with Metformin 500 mg/kg oral labelled as Met (500), Group 4 and Group 5 were treated with Stevioside $50 \mathrm{mg} / \mathrm{kg}$ and $100 \mathrm{mg} / \mathrm{kg}$ per oral called as Stv (50), Stv (100) respectively. The animals were kept without any treatment and tested every 7th day for HbA1c till the attainment of positive results i.e. HbA1c level $>7$ and was considered as day 1 of treatment (Rodríguez-Mañas et al., 1998). Respective treatments were then given orally for 1-28 days.

\section{Parameters}

Body weight and blood glucose (BG) of animals were recorded every 7th day from day 1 onwards. On day 28th, BG, serum triglycerides, serum cholesterol, HDL, LDL, HbA1c, blood urea nitrogen (BUN), blood creatinine, urine creatinine, urine albumin and total protein were estimated using various biochemical kits (Trinder, 1969). At the end of the study all the animals were sacrificed, both kidneys were isolated, right kidney of each rat was processed for histopathology while the left was used for AGE estimation.

\section{Histopathological examinations}

The kidneys were stored in $10 \%$ formalin; they were embedded in paraffin and cut into thin sections $(2-3 \mu)$ by microtome. The sections were stained with $\mathrm{H}$ and $\mathrm{E}$ stain. The sections were examined under light microscopy (200x and 400x) for gross pathology (Figarola et al., 2003).

\section{AGEs estimation in kidney tissues using the western blot technique}

The left kidneys, stored at $-80{ }^{\circ} \mathrm{C}$ were washed with cold phosphate buffer to remove blood stains and were homogenized to fine sample in the presence of liquid nitrogen using a tissue homogenizer. The tissue preparation was dissolved in rehydration buffer containing $7 \mathrm{M}$ urea, $2 \mathrm{M}$ thiourea, 2\% 3-[(3-cholamidopropyl) dimethylammonio]-1-propanesulfonate (CHAPS), $1 \%$ dithiothreitol (DTT), $40 \mathrm{mM}$ Tris, and centrifuged at $14000 \times \mathrm{g}$ for $1 \mathrm{~h}$ at $4^{\circ} \mathrm{C}$ in the centrifuge (HERMLE, Germany). The supernatant was collected and stored in aliquots at $-80{ }^{\circ} \mathrm{C}$. Protein concentration was estimated by using the Bradford method (Bhonsle et al., 2012). Sodium dodecyl sulfate-polyacrylamide gel electrophoresis (SDS PAGE) was used for separation of proteins according to their molecular weight. $40 \mu \mathrm{g}$ protein was loaded containing $1 \times$ loading dye in $1: 1$ ratio of volume of protein sample. The gel was transferred to the polyvinylidene fluoride (PVDF) membrane. The membrane was kept in ponceu stain to determine the transportation of protein from gel to PVDF membrane, PVDF membrane was blocked using skimmed milk at $37{ }^{\circ} \mathrm{C}$ for $1 \mathrm{~h}$ in the incuba- 
tor, after incubation skimmed milk was removed from the blot and CML anti Rabbit antibody was added to blot in the ratio of 1 : 1000 of skimmed milk and allowed to bind to blot by keeping for $3 \mathrm{~h}$ on rocker shaker. Blot was washed with $20 \%$ tween phosphate buffer (PBST) and then with PBS, pH 7.4 for 5 min at high speed for 2 times on rocker shaker. The blot was then treated with secondary antibody (1: 5000 of PBS), kept for $1 \mathrm{~h}$ on rocker shaker at low speed and again washed with PBST and PBS.

\section{Estimation of AGEs}

Immunoreactive bands were visualized using DAB system (Sigma) and documented by Bio-Rad G-800 densitometer.

\section{Statistical analysis}

The results were expressed as mean \pm S.E.M. The data were analyzed by one-way analysis of variance (ANOVA). For

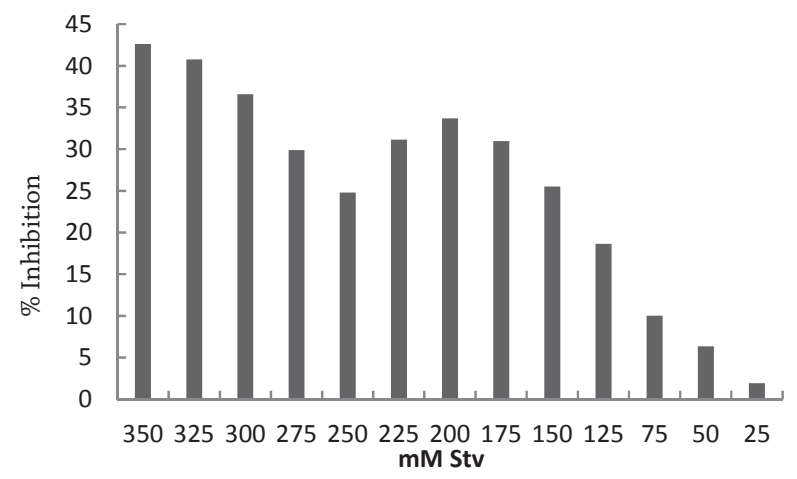

(A)

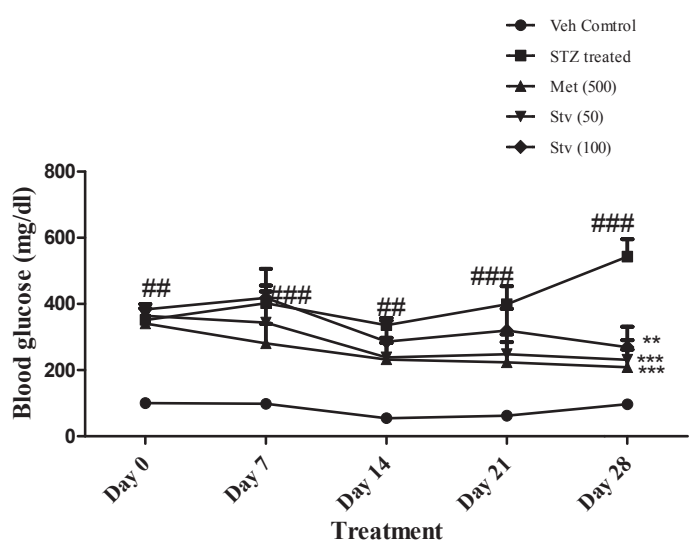

(C) body weight data, two way ANOVA was used. The ANOVA was followed by Dunnett's post hoc comparison tests for one way ANOVA and Bonferroni post-test was used for two way ANOVA, $p \leq 0.05$ were considered significant.

\section{Results}

\section{Effect of Stv (50 and $300 \mathrm{mM}$ ) on in vitro glycation}

The graph (Fig. 1A) represents \% inhibition of glycation v/s concentration of Stv. As the concentration is increased, inhibition of glycation was found to be increased. Maximum inhibition of $42.61 \%$ was obtained at the concentration of $350 \mathrm{mM}$.

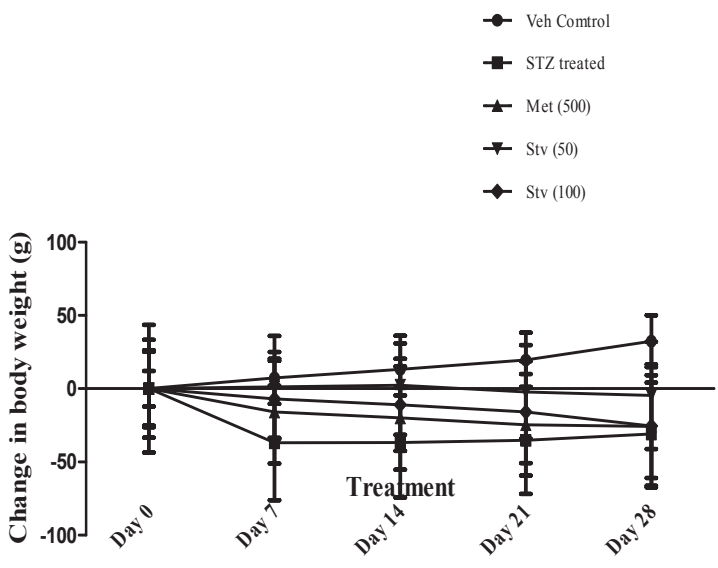

(B)

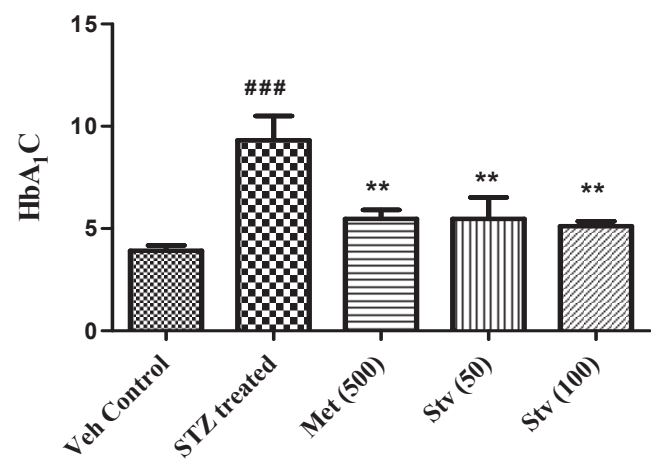

Treatment

(D)

Fig 1. (A) Percentage in vitro glycation inhibition by Stv. Effect of Stv on (B) Change in body weight, (C) Blood glucose level, (D) HbA1c level. Data are expressed as mean \pm SEM and were analyzed by two way ANOVA followed by a Bonferroni post test except HbA1c, which was done by one way ANOVA followed by Dunnett's post hoc test; \#\# $p<0.01$, \#\#\# $p<0.001$ as compared with vehicle control; ${ }^{* *} p<0.01,{ }^{* * *} p<0.001 \mathrm{Met}(500)$, Stv (50) and Stv (100) as compared with STZ treated.

\section{Effect of Stv (50 and $100 \mathrm{mg} / \mathrm{kg}$ ) on body weight (g)}

Diabetic rats showed non-significant reduction in body weight as compared to vehicle control rats. No significant increase was observed in Met (500 mg/kg) and Stv (50 and $100 \mathrm{mg} / \mathrm{kg}$ ) treated rats as compared to STZ treated rats (Fig. 1B).

\section{Effect of Stv (50 and $100 \mathrm{mg} / \mathrm{kg}$ ) on blood glucose level ( $\mathrm{mg} / \mathrm{dl})$}

Fig. $1 C$ shows effect of Stv and other treatments on blood glucose. BG level was significantly increased on day 7, 14, 21 and day 28 respectively in STZ treated as compared to vehicle control ( $p<0.01, p<0.001)$. Treatment with Met (500), Stv (50) and Stv (100) reduced blood glucose evident on day 7, 14, 21 and 28 as compared to STZ treated rats respectively $(p<0.001$, $p<0.01)$. BG was significantly reduced by all the treatments on day 28th $(p<0.001)$.

\section{Effect of Stv (50 and $100 \mathrm{mg} / \mathrm{kg}$ ) on $\mathrm{HbA1c}$}

STZ administered rats showed significant increase in HbAlc level as compared to vehicle control rats $(p<0.001)$ (Fig. 1D). 
Met $(500 \mathrm{mg} / \mathrm{kg})$ treatment exhibited significant reduction in HbA1c level as compared to control rats $(p<0.01)$. Diabetic rats treated with Stv (50 and $100 \mathrm{mg} / \mathrm{kg}$ ) also showed significant dose dependent reduction respectively as compared with STZ treated rats $(p<0.01)$.

\section{Effect of Stv (50 and $100 \mathrm{mg} / \mathrm{kg}$ ) on lipid profile}

The results are summarized in Fig. 2. STZ treated rats showed significant increase in triglyceride level $(\mathrm{mg} / \mathrm{dl})$ as compared to vehicle control group $(p<0.001)$. The treatments with Metformin as well as Stv (50 and $100 \mathrm{mg} / \mathrm{kg}$ ) demonstrated signif- icant reduction in the level of triglycerides as compared to STZ treated rats $(p<0.001, p<0.01, p<0.05)$. STZ treatment exhibited marked rise in cholesterol level (mg/dl) as well as LDL levels in STZ treated rats as compared to vehicle control rats $(p<0.05)$. Treatments with Stv $(50$ and $100 \mathrm{mg} / \mathrm{kg})$ reduced the cholesterol levels to vehicle control, as well as LDL was reduced significantly $(p<0.05)$, as compared to STZ treated rats. Treatments with Stv (50 and $100 \mathrm{mg} / \mathrm{kg}$ ) for four weeks in STZ treated rats showed significant rise in HDL levels as compared to STZ treated rats $(p<0.001$ and $p<0.05)$.

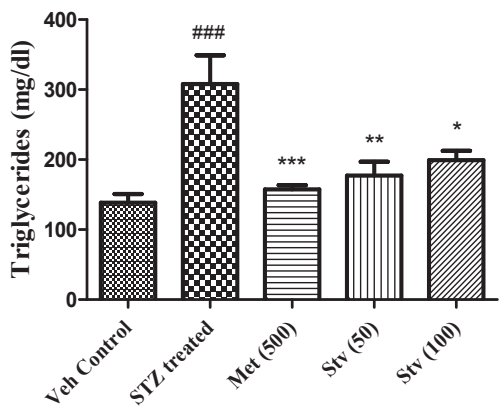

Treatment

(A)

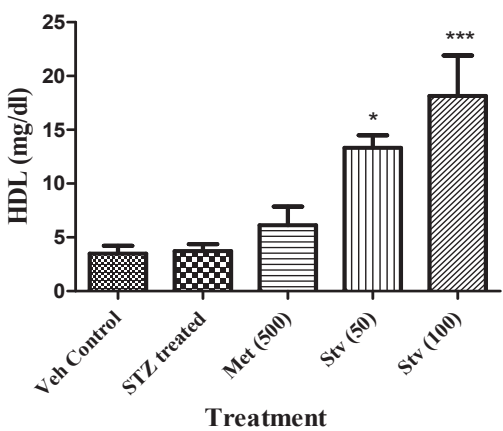

(C)

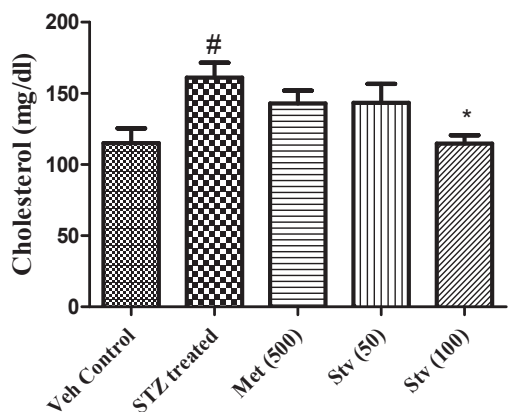

Treatment

(B)

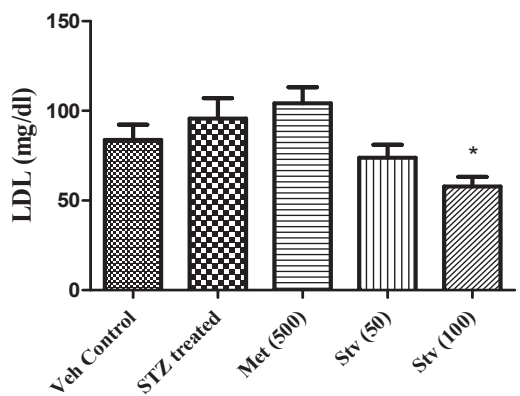

Treatment

(D)

Fig 2. Effect of Stv on lipid profile. (A) Triglyceride level, (B) Cholesterol level, (C) HDL levels, (D) LDL level. Data are expressed as mean \pm SEM and were analyzed by one way ANOVA followed by Dunnett's post hoc test; $\# p<0.05$, \#\# $p<0.01$ as compared with vehicle control, ${ }^{*} p<0.05,{ }^{* *} p<0.01,{ }^{*}$ ${ }^{* *} p<0.001$ Met (500), Stv (50) and Stv (100) as compared with STZ treated group.

\section{Effect of Stv (50 and $100 \mathrm{mg} / \mathrm{kg}$ ) on kidney function tests}

The effect of Stv on urine volume, urine albumin, total protein and $\mathrm{Ccr}$ (Creatine clearance) is shown in Fig. 3. Urine volume (24 h) was increased in STZ treated rats when compared to vehicle control rats $(p<0.001)$. Treatments with Stv $(50$ and $100 \mathrm{mg} / \mathrm{kg})$ and Met $(500 \mathrm{mg} / \mathrm{kg})$ normalized it $(p<0.05$, $p<0.01$ ). There was significant excretion of albumin and protein in urine in STZ treated rats as compared to normal rats $(p<0.01)$ indicating kidney injury. Treatment with Stv (50 and $100 \mathrm{mg} / \mathrm{kg}$ ) normalized urine albumin and total protein levels $(p<0.01, p<0.001, p<0.001))$. Met $(500 \mathrm{mg} / \mathrm{kg})$ treatment showed significant reduction in urinary protein $(p<0.001)$ though had no effect on urine albumin. Ccr $(\mathrm{mg} / 24 \mathrm{~h})$ was significantly increased in STZ treated rats as compared to vehicle control rats $(p<0.001)$. Treatment with Stv $(50$ and
$100 \mathrm{mg} / \mathrm{kg})$ and Met (500 mg/kg) significantly reduced Ccr $(p<0.001, p<0.05)$ as compared to STZ treated rats (Fig. 3D).

\section{Effect of Stv (50 and $100 \mathrm{mg} / \mathrm{kg}$ ) on histopathology of Kidney}

$\mathrm{H}$ and $\mathrm{E}$ stained [Fig. 4 (i) A-E] images of the kidney sections obtained from vehicle control group showed no abnormalities, STZ treated group showed increased vacuolization in epithelial tubular cells (as shown by black arrow in figure), increased thickness of messengial membrane with markedly increased cellularity. The increased vacuolization indicates glycosuria due to STZ treatment. Stv (50) showed no protection, this indicates, low dose Stv treatment for 28 days are insufficient to reverse the damage. Met $(500 \mathrm{mg} / \mathrm{kg})$ and Stv $(100 \mathrm{mg} / \mathrm{kg})$ treated group showed normal architecture of the tubules as well as glomerulus. 


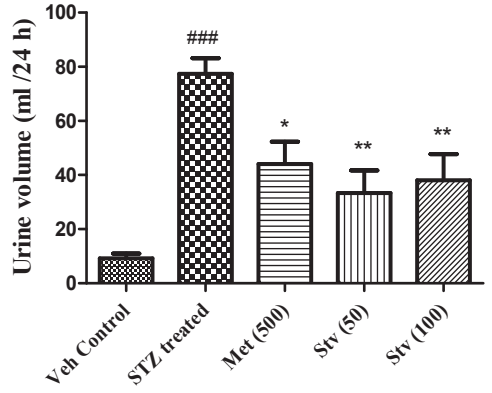

Treatment

(A)

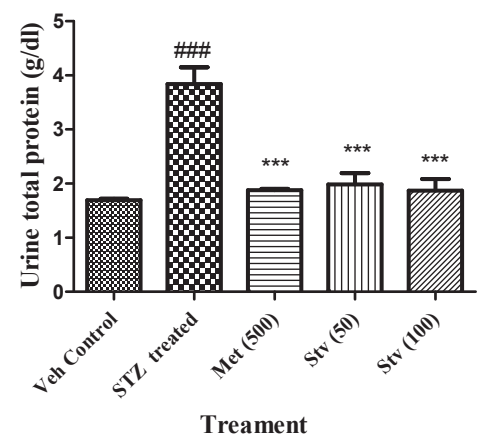

(C)

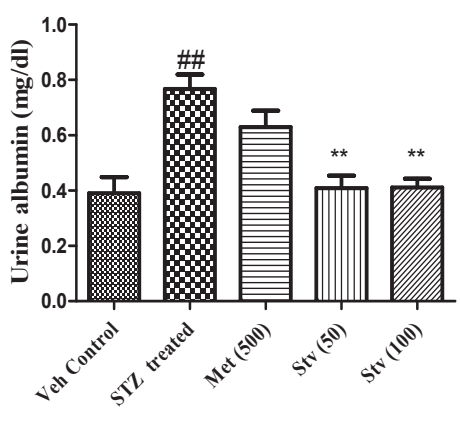

Treatment

(B)

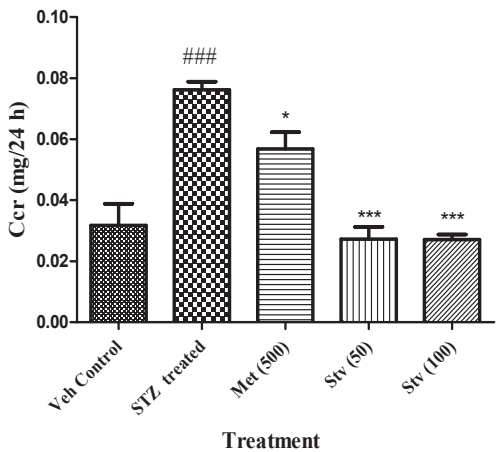

(D)

Fig 3. Effect of Stv on kidney function tests. (A) Urine volume level, (B) Urine albumin level, (C) Urine total protein levels, (D) Creatinine clearance (Ccr). Data are expressed as mean \pm SEM and were analyzed by one way ANOVA followed by Dunnett's post hoc test; \# $p<0.05$, \#\# $p<0.01$ as compared with vehicle control, ${ }^{*} p<0.05,{ }^{* *} p<0.01,{ }^{* * *} p<0.001$ Met (500), Stv (50) and Stv (100) as compared with STZ treated group.
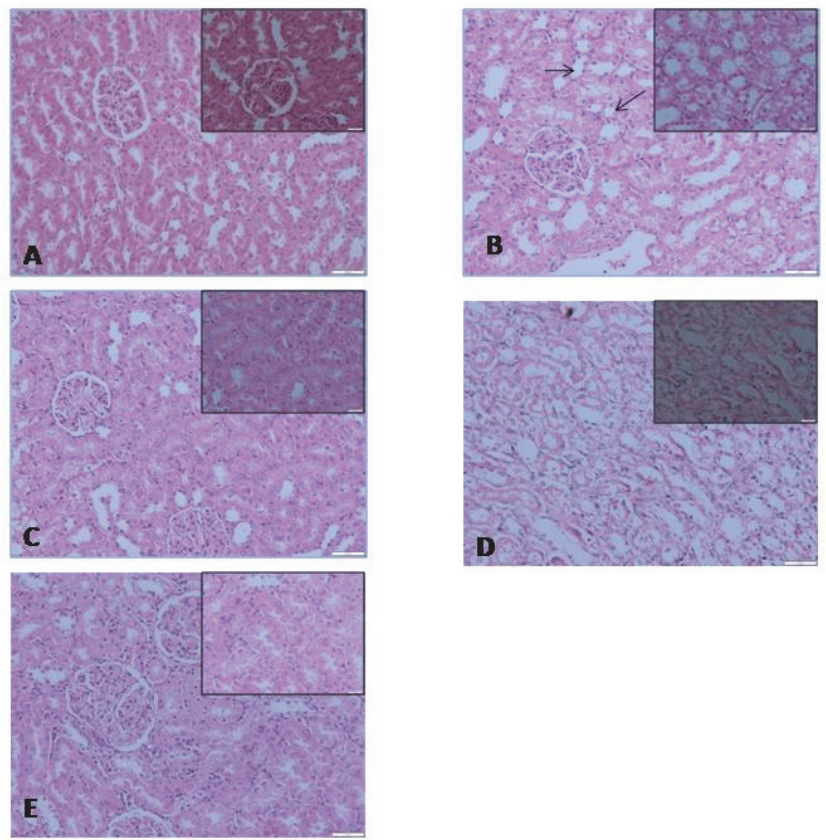

Fig 4. Sections of kidneys stained with $\mathrm{H}$ and $\mathrm{E}$ stain $(200 \times$ with inset at $400 \times)$, (A) Section of normal non diabetic kidney showing normal structure and architecture, (B) STZ treated group showing increased vacuolization in tubular epithelial cells with markedly increased cellularity, (C) Met (500) and E: Stv (100) rat kidney showed the normal architecture of glomeruli and tubular epithelium. (D) section of Stv (50) group rat kidney showed no protection against damage due to STZ administration. The scale bar represents $500 \mu \mathrm{m}$.

\section{Effect of Stv (50 and $100 \mathrm{mg} / \mathrm{kg}$ ) on AGEs (CML) using western blot}

CML expression was increased in STZ treated rats as compared to vehicle control rats. Treatments with Met $(500 \mathrm{mg} / \mathrm{kg})$ treatment and Stv $(100 \mathrm{mg} / \mathrm{kg})$ showed reduction in its expression. Stv (50) lowered its expression to a less extent than its high dose (Fig. 5).

\section{Discussion}

Clinically, there is a lack of available treatment to prevent formation of advanced glycation end products. The treatment of AGEs includes inhibitors of AGEs, drugs that prevent formation of AGEs and breakers of AGEs (Vlassara and Uribarri, 2014). Aminoguanidine emerged as potent advanced glycated end product inhibitor and also proved to prevent diabetic complications (Elbe et al., 2014; Vlassara and Uribarri, 2014). Due to its severe adverse effects such as antinuclear antibodies formation, deformities in the liver, gastrointestinal instability, rare vasculitis and pernicious like anemia, it was withdrawn from phase 1 clinical trial (Freedman et al., 1999; Friedman, 1999). Hence there is an urgent need to develop an effective antiglycation agent that is devoid of any side effects.

Stv has been reported for myriad of biological activities including diabetes (Geeraert et al., 2010; Hsieh et al., 2003; Jeppesen et al., 2000, 2002). The present study showed significant reduction of glucose in STZ treated rats by Stv in both the doses confirming its antidiabetic potential. The production of AGEs are closely associated with the pathogenesis of dia- 


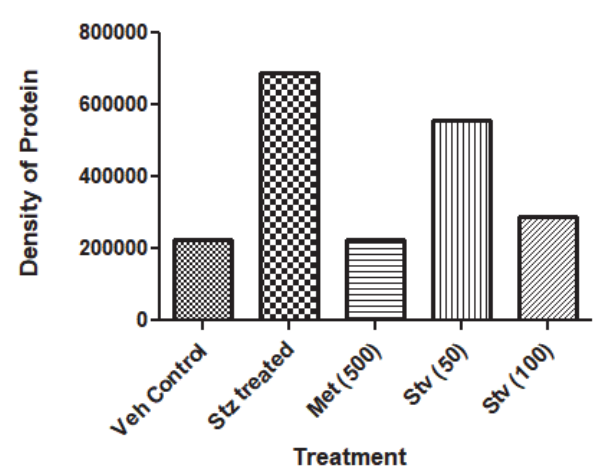

Fig 5. Effect of Stv (50 and $100 \mathrm{mg} / \mathrm{kg}$ ) on expression of AGEs- CML in renal tissue using western blot.

betic complications. The progression of diabetic complications can be achieved by inhibiting formation of AGEs. The present study demonstrated beneficial effect of Stv in attenuating formation of AGEs. Stv (50 and $100 \mathrm{mg} / \mathrm{kg}$ ) was administered for 28 days to rats with AGEs. Stv ( $25 \mathrm{mg} / \mathrm{kg} /$ day) has already been reported to exhibit anti-hyperglycemic activity due to it's insulinotropic and glucagonostic property (Jeppesen et al., 2003). STZ given at a dose of $35 \mathrm{mg} / \mathrm{kg}$ ip without nicotinamide developed Type I diabetes. It causes diabetes by the rapid depletion of $\beta$-cells, which leads to a reduction in the insulin release thereby causing blood glucose. Chronic diabetes leads to the autooxidation of glucose and causes glycation of protein (Goh and Cooper, 2008; Singh et al., 2001), we observed in the present study that $\mathrm{HbA1c}$ was markedly raised from day 21 of STZ administration ( $>7 \%$ HbA1c). Treatment with Stv for 28 days, showed inhibition of glycation as observed by significant reduction in $\mathrm{HbA} 1 c$, the results obtained are in parallel with the results obtained in our in vitro experiments. The possible mechanism of antiglycation activity of Stv appears to be the inhibition of physical interaction between glucose and amino acids. Stv is reported to compete with glucose for binding to carrier thereby inhibiting the entry of glucose into the cells, thus attenuating glycation (Rizzo et al., 2013). Though, we need to carry out more experiments to establish the mechanism of action of Stv at the molecular level.

Diabetes is most commonly associated with hyperlipidemia. The Framingham study demonstrated that atherosclerotic diseases were more frequent in diabetic patients than in non-diabetic ones (Kannel and McGee, 1979). Research made by Carr and Brunzell (2004) has shown that persistent and untreated diabetes prevents the ability of the body to clear chylomicrons, and leads to increase levels of low-density lipoprotein. Treatment with Stv exhibited anti-hyperlipidemic activity as observed by reduced level of triglycerides, cholesterol and LDL; more over Stv increased the level of HDL. The increase in lipid levels may be due to increased activity of hormone-sensitive lipases (HSL) which break down lipids and mobilize them from peripheral deposits. Hormones like ACTH and catecholamine stimulate them while insulin causes their inhibition (Saltiel and Kahn, 2001). Stv is previously reported to be insulinotropic (Jeppesen et al., 2002), which can be accounted for its favorable effect on lipid profile.

Chronic diabetes results in kidney disease (Sharma and Sharma, 2013). Increased AGEs concentration in the kidneys, results in structural changes in the kidneys which lead to nephropathy. One of the factors for induction of diabetic nephropathy is the expression of AGEs receptor Galactin 3 (AGE R3), it causes glomerulosclerosis and overactivation of podocytes (O'Seaghdha et al., 2013). In the present study, Stv showed inhibition of early renal dysfunction as measured by inhibition of increased urinary protein, urine albumin and creatinine clearance. The protective effects of Stv were confirmed by histopathology of the kidney. STZ treated kidney showed increased cellularity, increased mesangial cell, increase vacuolization of epithelial cells of tubular lumen due to high concentration of glucose in the filtered urine due to STZ treatment. High dose of Stv treatment showed the normal architecture of the kidney.

The protection in high dose was prominent then the low dose of Stv. Thus it is suggested that duration of administration of low dose of Stv should be increased to get the reversal of pathological changes. We further estimated CML, which is a major product of oxidative modification of glycation proteins (Baynes, 1991) and is considered as a useful marker for oxidative stress and long-term diabetes (Schleicher et al., 1997). A significant amount of studies has correlated rise in CML with that of microvascular and macrovascular complications such as, retinopathy (Hammes et al., 1999), nephropathy (Hammes et al., 1999) and cardiomyopathy (Schalkwijk et al., 2004). Western blot analysis of kidney proteins showed a marked rise in CML after 28 days of confirmed glycation (raised HbA1c). The present study demonstrated down-regulation of CML by Stv, dose-dependently, confirming its antiglycation potential. The effects obtained with a high dose of Stv (100) on BG and AGEs are comparable with that of metformin; with additional favorable effects on lipid and kidney profile. Further research should be undertaken to study the effect of Stv on other glycated protein to broaden our understating of usefulness of Stevia as anti-glycating agent.

\section{Conclusions}

Our study demonstrated that Stv exhibited antiglycating activity in vivo as well as in in vitro models. Along with its antiglycation property, its antihyperglycaemic, antihyperlipidemic and nephroprotective activities provide additional benefits. Further studies are necessary to understand the molecular mechanism of Stv.

\section{Conflict of interests}

The authors declare that there are no conflict of interests.

\section{Acknowledgments}

The authors would like to acknowledge BCUD, SPPU, Pune for funding the project. We would like to thank Prof. M. N. Navale, Founder, STES, Dr. K. G. Bothara, Principal, SIOP for providing the necessary facilities to carry out the preclinical research work and Dr. Mahesh Kulkarni, Scientist, Proteomics Facility Division of Biochemical Sciences, CSIR-National Chemical Laboratory, Pune, for helping us to perform western blot studies.

\section{References}

Ansari NA, Ali R (2011). Glycated lysine residues: a marker for nonenzymatic protein glycation in age-related diseases. Dis Markers 30(6): 317-324. DOI: 10.3233/DMA-2011-0791.

Baynes JW (1991). Role of oxidative stress in development of complications in diabetes. Diabetes 40(4): 405-412. DOI: $10.2337 /$ diab.40.4.405. 
Bhonsle HS, Korwar,AM, Kote SS, Golegaonkar SB, Chougale AD, Shaik ML, et al. (2012). Low plasma albumin levels are associated with increased plasma protein glycation and $\mathrm{HbA1} \mathrm{c}$ in diabetes. J Proteome Res 11(2): 1391-1396. DOI: 10.1021/pr201030m.

Bohlender JM, Franke S, Stein G, Wolf G (2005). Advanced glycation end products and the kidney. Am J Physiol Renal Physiol 289(4): F645-F659. DOI: 10.1152/ajprenal.00398.2004.

Boonkaewwan C, Ao M, Toskulkao C, Rao MC (2008). Specific immunomodulatory and secretory activities of stevioside and steviol in intestinal cells. J Agric Food Chem 56(10): 3777-3784. DOI: 10.1021/jf072681o.

Brownlee M (1995). Advanced protein glycosylation in diabetes and aging. Annu Rev Med 46(1): 223-234. DOI: 10.1146/annurev. med.46.1.223

Carr MC, Brunzell JD (2004). Abdominal obesity and dyslipidemia in the metabolic syndrome: importance of type 2 diabetes and familial combined hyperlipidemia in coronary artery disease risk. The J Clin Endocrinol Metab 89(6): 2601-2607. DOI:10.1210/ jc.2004-0432.

Chang PC, Tsai SC, Chong LY, Kao MJ (2014). N-Phenacylthiazolium bromide inhibits the advanced glycation end product (AGE)-AGE receptor axis to modulate experimental periodontitis in rats. J Periodontol 85(7): e268-e276. DOI: 10.1902/jop.2014.130554.

Daroux M, Prevost G, Maillard-Lefebvre H, Gaxatte C, D'Agati V, et al. (2010). Advanced glycation end-products: implications for diabetic and non-diabetic nephropathies. Diabetes Metab 36(1): 1-10. DOI:10.1016/j.diabet.2009.06.005.

Elbe H, Vardı N, Orman D, Taşlıdere E, Yıldız A (2014). Ameliorative effects of aminoguanidine on rat aorta in Streptozotocin-induced diabetes and evaluation of $\alpha$-SMA expression. Anatol J Cardiol 14(8): 679-684. DOI:10.5152/akd.2014.5047.

Elosta A, Ghous T, Ahmed N (2012). Natural products as anti-glycation agents: possible therapeutic potential for diabetic complications. Curr Diabetes Rev 8(2): 92-108. DOI: 10.2174/157339912799424528.

Figarola J, Scott S, Loera S, Tessler C, Chu P, Weiss L, Hardy J, Rahbar S (2003). LR-90 a new advanced glycation endproduct inhibitor prevents progression of diabetic nephropathy in streptozotocin-diabetic rats. Diabetologia 46(8): 1140-1152. DOI: 10.1007/s00125-003-1162-70.

Freedman BI, Wuerth JP, Cartwright K, Bain RP, Dippe S, Hershon K, et al. (1999). Design and baseline characteristics for the aminoguanidine Clinical Trial in Overt Type 2 Diabetic Nephropathy (ACTION II). Control Clin Trials 20(5): 493-510. DOI: 10.1016/S0197-2456(99)00024-0.

Friedman EA (1999). Advanced glycosylated end products and hyperglycemia in the pathogenesis of diabetic complications. Diabetes Care 22(Suppl. 2): B65-B71.

Gardana C, Simonetti P, Canzi E, Zanchi R, Pietta P (2003). Metabolism of stevioside and rebaudioside A from Stevia rebaudiana extracts by human microflora. J Agric Food Chem 51(22): 6618-6622. DOI: 10.1021/jf0303619.

Geeraert B, Crombe F, Hulsmans M, Benhabiles N, Geuns J, Holvoet P (2010). Stevioside inhibits atherosclerosis by improving insulin signaling and antioxidant defense in obese insulinresistant mice. Int J Obesity 34(3): 569-577. DOI: 10.1038/ ijo.2009.261.

Goh SY, Cooper ME (2008). The role of advanced glycation end products in progression and complications of diabetes. J Clin Endocrinol Metab 93(4): 1143-1152. DOI: 10.1210/jc.2007-1817.

Gregersen S, Jeppesen PB, Holst JJ, Hermansen K (2004). Antihyperglycemic effects of stevioside in type 2 diabetic subjects. Metabolism 53(1): 73-76. DOI: 10.1016/j.metabol.2003.07.013.

Hammes HP, Brownlee M, Lin J, Schleicher E, Bretzel R (1999). Diabetic retinopathy risk correlates with intracellular concentrations of the glycoxidation product $\mathrm{Ne}$-(carboxymethyl) lysine independently of glycohaemoglobin concentrations. Diabetologia 42(5): 603-607. DOI: 10.1007/s001250051201.

Hsieh MH, Chan P, Sue YM, Liu JC, Liang TH, Huang TY, et al. (2003). Efficacy and tolerability of oral stevioside in patients with mild essential hypertension: a two-year, randomized, placebocontrolled study. Clin Ther 25(11): 2797-2808. DOI: 10.1016/ S0149-2918(03)80334-X.
Jakus V, Rietbrock N (2004). Advanced glycation end-products and the progress of diabetic vascular complications. Physiol Res 53(2): 131-142.

Jeppesen PB, Gregersen S, Alstrup K, Hermansen K (2002). Stevioside induces antihyperglycaemic, insulinotropic and glucagonostatic effects in vivo: studies in the diabetic Goto-Kakizaki (GK) rats. Phytomedicine 9(1): 9-14. DOI: 10.1078/0944-7113-00081.

Jeppesen PB, Gregersen S, Poulsen C, Hermansen K (2000). Stevioside acts directly on pancreatic $\beta$ cells to secrete insulin: Actions independent of cyclic adenosine monophosphate and adenosine triphosphate - sensitivie $\mathrm{K}+$-channel activity. Metabolism 49(2): 208-214. DOI: 10.1016/S00260495(00)91325-8.

Jeppesen PB, Gregersen S, Rolfse S, Jepsen M, Colombo M, Agger A, et al. (2003). Antihyperglycemic and blood pressure-reducing effects of stevioside in the diabetic Goto-Kakizaki rat. Metabolism 52(3): 372-378. DOI: 10.1053/meta.2003.50058.

Kannel WB, McGee DL (1979). Diabetes and cardiovascular disease: the Framingham study. Jama 241 (19): 2035-2038. DOI: 10.1001/ jama.1979.03290450033020.

Liu JC, Kao PK, Chan P, Hsu YH, Hou CC, Lien GS, et al. (2003). Mechanism of the antihypertensive effect of stevioside in anesthetized dogs. Pharmacol 67(1): 14-20. DOI: 10.1159/000066782.

Naowaboot J, Pannangpetch P, Kukongviriyapan V, Kongyingyoes B, Kukongviriyapan U (2009). Antihyperglycemic, antioxidant and antiglycation activities of mulberry leaf extract in streptozotocininduced chronic diabetic rats. Plant Food Hum Nutr 64(2): B116B121. DOI: 10.1007/s11130-009-0112-5.

O'Seaghdha CM, Hwang SJ, Ho JE, Vasan RS, Levy D, Fox CS (2013). Elevated galectin-3 precedes the development of CKD. J Am Soc Nephrol 24(9): 1470-1477. DOI: 10.1681/ASN.2012090909.

Peppa M, Uribarri J, Vlassara H (2008). Aging and glycoxidant stress. Hormones (Athens) 7(2): 123-132. DOI: 10.1007/BF03401503.

Pinhas-Hamiel O, Levek-Motola N, Kaidar K, Boyko V, Tisch E, Mazor-Aronovitch K, et al. (2015). Prevalence of overweight, obesity and metabolic syndrome components in children, adolescents and young adults with type 1 diabetes mellitus. Diabetes Metab Res Rev 31(1): 76-84. DOI: 10.1002/dmrr.2565.

Rizzo B, Zambonin L, Angeloni C, Leoncini E, Vieceli Dalla Sega F, et al. (2013). Steviol glycosides modulate glucose transport in different cell types. Oxid Med Cell Longev 2013: 348169. DOI: $10.1155 / 2013 / 348169$.

Rodríguez-Mañas L, Angulo J, Peiró C, Llergo JL, SánchezFerrer A, López-Dóriga P, Sánchez-Ferrer CF (1998). Endothelial dysfunction and metabolic control in streptozotocin-induced diabetic rats. Br J Pharmacol 123(8): 1495-1502. DOI: 10.1038/ sj.bjp.0701749.

Sajithlal G, Chithra P, Chandrakasan G (1998). Effect of curcumin on the advanced glycation and cross-linking of collagen in diabetic rats. Biochem Pharmacol 56(12): 1607-1614. DOI: 10.1016/ S0006-2952(98)00237-8.

Saltiel AR, Kahn CR (2001). Insulin signalling and the regulation of glucose and lipid metabolism. Nature 414(6865): 799-806. DOI: $10.1038 / 414799 a$.

Schalkwijk CG, Baidoshvili A, Stehouwer CD, van Hinsbergh VW, Niessen HW (2004). Increased accumulation of the glycoxidation product $\mathrm{N} \varepsilon$-(carboxymethyl) lysine in hearts of diabetic patients: generation and characterisation of a monoclonal anti-CML antibody. Biochim Biophys Acta 1636(2-3): 82-89. DOI: 10.1016/j.bbalip.2003.07.002.

Schleicher ED, Wagner E, Nerlich AG, (1997). Increased accumulation of the glycoxidation product $\mathrm{N}$ (epsilon)-(carboxymethyl) lysine in human tissues in diabetes and aging. J Clin Invest 99(3): 457-468. DOI: $10.1172 /$ JCI119180.

Sehar I, Kaul A, Bani S, Pal HC, Saxena AK (2008). Immune up regulatory response of a non-caloric natural sweetener, stevioside. Chem Biol Interact 173(2): 115-121. DOI: 10.1016/j. cbi.2008.01.008

Sharma V, Sharma P (2013). Role of different molecular pathways in the development of diabetes-induced nephropathy. J Diabetes Metab S9: 004. DOI: 10.4172/2155-6156.S9-004. 
Singh R, Barden A, Mori T, Beilin L (2001). Advanced glycation endproducts: a review. Diabetologia 44(2):129-146. DOI: 10.1007/ s001250051591.

Stoyanova S, Geuns J, Hideg É, Van Den Ende W (2011). The food additives inulin and stevioside counteract oxidative stress. Int J Food Sci Tech 62(3): 207-214. DOI: 10.3109/09637486.2010.523416.
Trinder P (1969). Determination of blood glucose using an oxidaseperoxidase system with a non-carcinogenic chromogen. J Clin Pathol 22(2): 158-161. DOI: 10.1136/jcp.22.2.158.

Vlassara H, Uribarri J (2014). Advanced glycation end products (AGE) and diabetes: cause, effect, or both? Curr Diab Rep 14(1): 453. DOI: 10.1007/s11892-013-0453-1. 